PALABRAS CLAVE

Clases sociales

Estructura social

Movilidad social

Aspectos económicos

Aspectos políticos

Problemas sociales

Medio urbano

Chile

Kathya Araujo

Profesora, Universidad Academia de Humanismo Cristiano

œkaraujo@academia.cl

Danilo Martuccelli

Profesor, Universidad París Descartes

Centro de Investigaciones sobre los Vínculos Sociales (CERLIS)

Centro Nacional de Investigación

Científica (CNRS)

○ danilo.martuccelli@univ-lille3.fr
REVISTA CEPAL 103 • ABRIL 2011

\section{La inconsistencia posicional: un nuevo concepto sobre la estratificación social}

\author{
Kathya Araujo y Danilo Martuccelli
}

N

obre la base de una investigación empírica realizada mediante un centenar de entrevistas semidirectivas con actores pertenecientes a distintos grupos sociales, en este artículo se propone y argumenta el uso de un nuevo concepto para abordar la estratificación social en la sociedad chilena actual, cual es la "inconsistencia posicional". Con esta noción se designa un sentimiento de inquietud posicional más o menos permanente y generalizado en la gran mayoría de los estratos sociales, cuyas características específicas lo distinguen de otros procesos similares (temor estatutario, vulnerabilidad, exclusión, movilidad, entre otros). Una experiencia que, aunque común en su expresión, es empero engendrada por una pluralidad de factores dando lugar a un importante fenómeno estructural. 
I

\section{Introducción}

En este artículo se desarrolla la idea de que el estudio de la estratificación social en América Latina debe prolongarse tomando en consideración una experiencia que, sin ser exclusiva de la región, presenta en ella características particulares y decisivas. Sobre la base del caso chileno, se mostrará la existencia de lo que aquí se denomina una experiencia de "inconsistencia posicional", que es común y transversal a distintos estratos sociales.

El desarrollo de esta tesis se efectúa en cuatro tiempos. En la sección II se presenta brevemente el análisis que conduce a eslabonar la complejidad creciente de las situaciones sociales con el estudio de las inquietudes posicionales. En la sección III, y una vez subrayado el carácter común de lo que aquí se llama la inconsistencia posicional en los diferentes estratos sociales, se la distingue de otras nociones próximas. En la sección IV se presentan las distintas amenazas que, paradójicamente, dan cuenta a la vez de su transversalidad y de su diversidad en los diferentes sectores estudiados. Por último, y a manera de conclusión, se mencionan algunas de las consecuencias que la experiencia de la inconsistencia posicional tiene como desafío ordinario en la vida de la mayoría de los individuos entrevistados.

Este trabajo se funda en una investigación empírica realizada en Chile (en las ciudades de Santiago, Concepción y Valparaíso) entre los años 2007 y 2009, mediante un centenar de entrevistas semidirectivas a hombres y mujeres de 30 a 55 años, pertenecientes a sectores populares urbanos y a las capas medias y altas. Por lo general, en las ciencias sociales no se recurre a métodos cualitativos para estudiar la estratificación social. En efecto, en la mayor parte de los trabajos se advierte una voluntad estadística de agregación de individuos en un número reducido de grupos (clases o estratos) que diseñan la arquitectura posicional de una sociedad. En Chile existen numerosos ensayos de este tipo, en que - según las opciones teóricas elegidas - se subraya el peso decisivo del trabajo, el ingreso, el consumo o la cultura (o combinaciones de estos factores) a la hora de diseñar el perímetro de las grandes posiciones sociales. Para efectuar clasificaciones de esta índole, las técnicas estadísticas son sin duda indispensables. Pero lo que interesa en este artículo es destacar un fenómeno diferente y llamar la atención sobre una dimensión subjetiva relativamente descuidada en muchos estudios sobre la estratificación social stricto sensu. Dimensión en la que, sin cuestionar la pertinencia de las divisiones sociales, será necesario reconocer, detrás de la diversidad de posiciones sociales, la presencia de una experiencia común transversal de inconsistencia posicional como característica mayor de la posición social en el Chile de hoy.

\section{II}

\section{De la estratificación social a una experiencia posicional transversal}

Si los intentos por encontrar una visión esquemática y más o menos piramidal de los grandes posicionamientos de clase no han desaparecido en América Latina, lo que

$\square$ En este artículo se presenta parte de los resultados del proyecto de investigación Fondo Nacional de Desarrollo Científico y Tecnológico (Fondecyt) 1085006 "Procesos de individuación y configuración de sujeto en la sociedad chilena actual". Los autores agradecen las evaluaciones anónimas, así como los comentarios y sugerencias enriquecedoras respecto de la primera versión de este artículo. se impone progresivamente es una visión más compleja de los emplazamientos sociales. Incluso en los estudios en que se intenta delimitar las grandes posiciones de clase en el continente a partir de la primacía de relaciones de tipo capitalista, aparece la necesidad de hacer intervenir una diversidad de otros factores estructurales (Portes y Hoffman, 2007). A la tradicional coexistencia de distintos modos de producción (moderno, pequeña empresa, y otros), se añade una multiplicación de los recursos que dan acceso al poder, el prestigio o la riqueza, 
lo que incluye tanto diferentes modos de remuneración como distintas formas de contrato de trabajo (y los diferenciales de cobertura social y protección que estos implican). El resultado es la toma de conciencia de que para dar cuenta con mayor precisión de la estratificación social en América Latina es indispensable movilizar una heterogeneidad de factores. Lo anterior conduce progresivamente a una tensión entre los estudios en que se definen las dinámicas de clase y los trabajos con enfoque más descriptivo (Dubet y Martuccelli, 2000). Es precisamente en este sentido que es importante la oposición entre las seis grandes clases sociales descritas por Portes y Hoffman (2007) y las 45 categorías sociales distinguidas por León y Martínez (2007) en su propuesta de clasificación de los actores sociales en Chile.

Nos encontramos así ante un movimiento general de complejización de la heterogeneidad efectiva de las situaciones sociales, que por el momento se ha hecho sobre todo en América Latina otorgándole una atención renovada a otras formas de capital o activos totales (assets). A la tríada (empleo, ingresos, educación) se le añade una pluralidad de otros factores, como el capital social, la naturaleza de las redes sociales, las formas de pertenencia, los diferenciales de estereotipo social, la capacidad de acceso y control de los códigos culturales dominantes, la importancia de los lugares de residencia (los barrios), el hecho de ser o no propietario de su vivienda, los efectos que la vida personal y familiar (separaciones, decesos, y otros) tienen en las trayectorias sociales. Se suma, además, el papel mayúsculo que el consumo ha tenido en la región, no solo en el proceso de desdibujamiento relativo de las fronteras entre los grupos sociales, sino también en la aparición de nuevas formas de inclusión simbólica entre los sectores populares (García Canclini, 1995; Aguilar, 2009), al punto de que, en Chile como en otros países, ha terminado por imponerse en la opinión pública un modelo de estratificación social generado a partir de los estudios de mercado, clasificándose a los chilenos en las categorías $\mathrm{ABC} 1$ (10\% - élite y clase media alta), $\mathrm{C} 2$ (20\% - clase media media), C3 (25\% - clase media baja), D (35\% - pobreza) y E (10\% - extrema pobreza) (Rasse, Salcedo y Pardo, 2009).

Si bien la idea de una pirámide posicional sigue estando presente en los estudios sobre la estratificación social, lo que se consolida progresivamente es la toma de conciencia de la existencia de una gran diversidad de posiciones intermedias. O mejor dicho, la multiplicación de los factores de posicionamiento social estudiados hace cada vez más difícil saber quién está verdaderamente "arriba" o "abajo", que los posicionamientos híbridos se incrementen y que los actores puedan conocer de manera simultánea y contradictoria movilidades "ascendentes" o "descendentes" en diversos ámbitos sociales; y ello incluso en la mayor parte de los estratos sociales. A la tradicional división estamental entre grupos - presente sin embargo a nivel del imaginario de los individuos (Araujo, 2009) y evidente en términos de deciles de ingreso- es preciso añadir la visión de un continuo de posiciones sociales sin cambio brusco entre ellas (AIM, 2000). Una realidad que en parte se refleja en el hecho de que entre el $60 \%$ y el $80 \%$ de los chilenos se consideran como pertenecientes a las "clases medias", lo que le da a este grupo social una predominancia efectiva a la hora de definir el perfil de la sociedad chilena actual (Torche y Wormald, 2007; León y Martínez, 2007).

Sin embargo, aunque en Chile es importante la generalización de este sentimiento de pertenencia a las clases medias, ello no debe hacer olvidar lo esencial, a saber, la fuerte dispersión y heterogeneidad de experiencias sociales observables en el seno de un mismo grupo social, ya sea del mundo popular o de las denominadas capas medias (Barozet y Espinoza, 2009), lo que invita a reconocer la singularización creciente de las experiencias dentro de los distintos estratos sociales (Espinoza, 2002).

No obstante la importancia de este tipo de abordajes en que se enfatiza la singularización de las posiciones sociales, en la presente investigación se revela la existencia de un fenómeno transversal a la gran mayoría de ellas. En efecto, con excepción de una élite durable y globalmente protegida - en un país caracterizado por una fuerte concentración de diversas formas de poder (Molina, 2005)—, la mayor parte de los individuos sienten que su posición es extremadamente permeable al cambio y sujeta al deterioro social. Es la conciencia generalizada de esta situación lo que define una de las grandes características posicionales de los chilenos hoy en día: el sentimiento de que todas las posiciones pueden sufrir procesos activos de desestabilización. 


\section{III \\ ¿Qué es la inconsistencia posicional?}

En el corazón de esta experiencia de inconsistencia posicional se encuentra el sentimiento de que todo puede, todo el tiempo, cambiar. Se trata de una preocupación posicional permanente, una actitud cotidiana de inquietud que refleja una sociedad atravesada por sentimientos plurales de inestabilidad. La inconsistencia posicional es una inquietud multiforme, plural en sus fuentes, por lo general constante, que da lugar a una atmósfera de preocupación posicional común a un gran número de individuos situados en distintos estratos sociales. Para delimitar esta experiencia vale la pena diferenciarla de otras nociones en apariencia próximas: infraclase o marginalidad; vulnerabilidad o exclusión; temor estatutario o inconsistencia de estatus; movilidad social.

i) La inconsistencia posicional, pese al papel mayor que ciertos testimonios otorgan al aspecto urbano o económico, se encuentra en las antípodas de los trabajos sobre la infraclase o la subclase (the underclass). En efecto, la inconsistencia en cuestión no se relaciona exclusivamente con una transformación económica (el paso de una economía urbana e industrial a una economía periurbana dominada por los servicios), ni con una expresión esencialmente urbana (Wilson, 1987 y 1996). Si se considera la experiencia de la periferia urbana del Gran Santiago, en ella no se ha engendrado ninguna identidad urbana específica y la inconsistencia posicional que aqueja a sus miembros no puede reducirse solo a un proceso económico que habría polarizado sobre nuevas bases la estructura social. Por el contrario, es como ciudadanos, por lo general insertos en el mercado de trabajo y compartiendo el criterio dominante (mainstream) de valores de la sociedad chilena, que estos habitantes expresan su malestar, frustración e inconsistencia posicional. El problema no es que no "son" como los otros, el problema es que percibiéndose colectivamente como los otros sienten que sus posiciones son particularmente inestables. La mayoría de los habitantes entrevistados en estos barrios, cualquiera que haya sido su situación económica, eran trabajadores formales (o tenían miembros de su familia en este sector). Por lo tanto, se encuentran definidos menos por la exterioridad o la informalidad económica (globalmente baja en Chile) que por su escasa calificación y bajos ingresos. El problema no es que están "afuera" (out). El problema es que estando "dentro" (in) se sienten frágiles.

Es en este mismo sentido que la noción de inconsistencia posicional se distingue de la "marginalidad". En ella, como se sabe, se subrayó una dimensión estructural particular: los límites del sistema capitalista en la región para absorber, a diferencia de los países centrales, el excedente de mano de obra proveniente del campo (Nun, 1969; Quijano, 1971). La gran característica de la inconsistencia posicional no concierne únicamente a un número reducido de actores (que habrían sido "olvidados" o "abandonados" por el progreso), sino a un grupo numéricamente muy importante de actores que perciben su posición a través de un sentimiento sui géneris de inconsistencia.

ii) La inconsistencia posicional designa un proceso social amplio y transversal a muchos estratos sociales, aun cuando — como se discutirá más adelante- las fuentes y su peso sean diversos. A diferencia de ciertos estudios de estratificación social en que la "vulnerabilidad" — por lo general definida exclusivamente en relación con la pobre$\mathrm{za}$ - ha sido restringida al sector popular o incluso a un proletariado informal (Contreras y otros, 2005; Torche y Wormald, 2007), la inconsistencia define una experiencia social propia de muchos otros estratos sociales. Ciertamente, en algunos estudios se ha mostrado cómo dentro del mundo popular (el a veces denominado "sector D") existe, por una parte, una vulnerabilidad eventual y, por otra, una vulnerabilidad crónica. Pero a pesar de esta distinción, lo importante es que - como se evidencia fehacientemente en los estudios de la Encuesta de Caracterización Socioeconómica (CASEN) - la vulnerabilidad designa siempre una experiencia bien acotada socialmente (Ramos y otros, 2004). Por supuesto, las razones de este uso restringido de la noción son legítimas, pero en vista del material cualitativo que aquí se ha producido parece indispensable recurrir a una noción más amplia para designar el sentimiento de inquietud posicional expresado por la gran mayoría de los individuos. 
Una distinción similar se impone a propósito de la noción de "exclusión". Aquí, y pese a la fuerte polisemia del término, es posible afirmar que lo que se subraya es un proceso de fragilización que concierne de forma progresiva a grupos sociales perfectamente adaptados a la sociedad moderna y que son, sin embargo, víctimas de la coyuntura económica y sobre todo de la crisis del empleo. En este sentido, la exclusión es una noción que, sin negar la existencia de un "cuarto mundo" o de una "pobreza" extrema, se focaliza en dirección de grupos sociales más integrados. Pero en esta extensión analítica, y a pesar de la voluntad de dar con una definición dinámica y multidimensional de la exclusión, en el fondo del análisis se privilegia la tesis de la existencia de una crisis del lazo social y se la relaciona, tarde o temprano, esencialmente con la transformación de las formas de integración aseguradas por el empleo (Castel, 1995; Paugam, 1996). Una experiencia que está muy lejos de hacer justicia a las características propias del mercado de trabajo en América Latina y, en algunos países, a la violencia del proceso de desclasamiento (Minujín, 1993).

iii) Pero la inconsistencia posicional (aun cuando integre a veces este proceso) no se reduce tampoco a un mero "temor estatutario" o a la "inconsistencia de estatus". Si bien aspectos de esta inquietud están por momentos presentes en lo que atañe a la inconsistencia posicional, esta última es sin embargo de otra índole. En el primer caso, la ansiedad se produce en medio de posiciones sociales que son percibidas como sólidas, y es la solidez de los lugares y la dificultad para acceder a ellos y ocuparlos lo que origina el temor estatutario, la necesidad de fabricarse una personalidad orientada a la defensa activa y permanente del estatus, como ha sido magníficamente establecido a propósito del cortesano o del hombre de la organización (Elias, 1982; Whyte, 1957; Kocka, 1989, Boltanski, 1982). Por el contrario, en el caso de la inconsistencia posicional es el propio emplazamiento social el que se percibe como poroso y susceptible de deterioro.

En el segundo caso, la noción comparte con la inconsistencia de estatus la característica de señalar una pérdida de legibilidad de los estatus, el hecho de que aparezcan contradicciones entre los diversos registros —económicos o simbólicos- de una posición, que los posicionamientos híbridos se incrementen y que los actores puedan conocer de manera simultánea y contradictoria movilidades "ascendentes" o "descendentes" en diversos ámbitos sociales, y ello incluso en la mayor parte de los estratos sociales. Sin embargo, aun compartiendo estos aspectos, en el caso de la inconsistencia posicional, más que las contradicciones, lo que se subraya es la difuminación de los lugares ocupados por los actores y el desasosiego concomitante.

La situación de las "clases medias" en Chile permitirá precisar esta distinción. Este grupo social se caracteriza por un tránsito —insuficientemente teorizado - en lo que a su ansiedad se refiere. Durante mucho tiempo, la ansiedad específica de este grupo social, ubicado por definición en una situación intermedia, fue teorizada más en términos estatutarios que posicionales. Ser de clase media era, antes que cualquiera otra cosa, poseer y defender un estatus social (Portocarrero, 1998). En las últimas décadas ha ocurrido una verdadera transición. Sin desaparecer, la tradicional ansiedad estatutaria propia de las clases medias se agudiza en un temor de "caer" (Ehrenreich, 1989), pero sobre todo cede el paso, sigilosamente, a la afirmación de un sentimiento distinto de inconsistencia posicional. Si los términos empleados son a veces similares, puesto que en ambos casos se vislumbra el temor de "caer" socialmente, en el fondo los procesos no son los mismos. En el primer caso, la ansiedad se origina en la voluntad de defender los "privilegios" o "derechos", incluso la accesibilidad a un estatus (Lomnitz y Melnick, 1991). En el segundo caso, se trata de multiplicar recursos o soportes (económicos, políticos o relacionales) con el fin de apuntalar y solidificar una posición social que se percibe como inconsistente mediante un conjunto de estrategias relacionales (Barozet, 2002; Sánchez, 2009). En el primer caso, es la famosa "decencia” de las clases medias latinoamericanas y las fronteras simbólicas que pueden construirse alrededor de ella lo que traza la frontera estatutaria; en el segundo, no se trata tanto de mantener una posición dada, sino de mantener la posición misma - en verdad, de lo que se trata aquí es de mantenerse en una posición a la que, debido a su carácter inestable, es imperioso apuntalar por medio de estrategias individuales y colectivas.

iv) Por último, el sentimiento generalizado de inconsistencia de las posiciones sociales no puede reducirse únicamente a un efecto directo de la movilidad social ascendente o descendente o al movimiento de entrada y salida de la pobreza. Esta distinción analítica es tanto más importante dado que la sociedad chilena 
se caracteriza, en las últimas décadas, por altas tasas de movilidad social en un contexto de marcada segmentación urbana y acentuada desigualdad en el ingreso (Torche, 2005; Contreras, D., O. Larrañaga y J. Litchfield, 2001). La tasa de movilidad, medida en función de la distribución del ingreso, es muy decidora en el corto plazo: entre 1996 y 2006 solo un $18,9 \%$ de los chilenos estudiados se mantuvo en sus deciles de ingreso originales 10 años después (Arzola y Castro, 2009, págs. 70-72). Y esta movilidad, si bien en proporciones distintas, es visible tanto en el decil más pobre (en el lapso de 10 años, solo un $28,1 \%$ se mantuvo en esta misma posición, lo que testimonia un importante "ascenso" social) como en el decil más rico (donde solo el 45,4\% se mantuvo en el mismo décil de ingreso una década después). Esto es, que incluso si la movilidad es mayor entre los sectores más pobres con respecto a los más ricos, en todos ellos es visible una muy importante tasa de movilidad.

Sin lugar a dudas, esta realidad participa del sentimiento de inconsistencia posicional expresado por los entrevistados. Pero aquí también el fenómeno aparece como más amplio, no solo como lo veremos a causa de la pluralidad de fuentes evocadas, sino también porque los miembros de sectores medios y sobre todo altos que aquí se han entrevistado manifestaron una profunda inquietud posicional, pese al hecho de que la movilidad intergeneracional en Chile (las probabilidades de transitar de los quintiles más bajos a los más altos y viceversa) sea baja (Núñez y Miranda, 2009). Esto significa que si la movilidad entre grupos es alta, en su extremo superior la sociedad chilena aparece como particularmente poco abierta a la circulación de las elites, puesto que se materializan diferentes mecanismos de "cierre" (Contardo, 2008). Y sin embargo, pese a que en Chile existen en lo alto de la "pirámide" social barreras que aparecen como infranqueables, esto no elimina la presencia de una inquietud ante la inconsistencia posicional entre los miembros de este grupo.

En resumen, la inconsistencia posicional describe un degradé de situaciones, ya que no todos los actores la experimentan con la misma intensidad y, sobre todo, no todos a causa de los mismos factores. Esta inconsistencia es muy distinta según los períodos históricos y obviamente las capas sociales, pero también lo es en función de los factores que son tomados en cuenta: al binomio tradicional de la economía y los lazos sociales, es imperioso añadirle, a fin de restituir la complejidad de esta experiencia, otros factores de índole política, cultural y urbana.

\section{IV}

\section{La generalización diferenciada de la inconsistencia posicional}

\begin{abstract}
La inconsistencia posicional designa pues una experiencia particular, mezcla a la vez de estado y de proceso. Un estado: el sentimiento de inconsistencia es constante entre los actores y ello a pesar de la bonanza de la que pueden hacer gala bajo muchos aspectos. Un proceso: la inconsistencia, incluso cuando toma formas abruptas, es siempre el resultado de una serie de fases que debilitan o deterioran progresivamente una posición. Para comprender esta doble realidad y su generalización diferenciada en la sociedad chilena actual, es útil distinguir cuatro grandes factores.
\end{abstract}

\section{Desestabilizaciones socioeconómicas}

En términos estructurales, la economía chilena experimentó desde los años ochenta un importante proceso de disminución de los sectores agrícolas, de transformación en el trabajo manual (acompañada de una importante reducción de la mano de obra y una notoria transformación interna de este grupo) y de tercerización del empleo que fue aparejada del incremento del sector privado y el descenso del empleo público. Una transformación que, en términos generales, ha supuesto que el empleo haya perdido capacidades de protección, acentuándose una tendencia a la precarización estatutaria en la estructura ocupacional, aun cuando en Chile el fenómeno sea más complejo y menos unidireccional de lo que muchas veces se afirma. Un proceso de transformación, a la vez de "mejora" y de "deterioro", probablemente no ajeno a la aparición de formas espurias de movilidad social, como es el caso de individuos que se convierten en empresarios y expresan una nostalgia por la antigua 
condición obrera, o de comerciantes que añoran su situación en el agro (Kessler y Espinoza, 2007, pág. 285). Ello hace posible plantear la hipótesis de que lo que subyace a estas opiniones es una forma difusa de conciencia de un incremento, pese a la movilidad "objetiva" experimentada, del sentimiento de una inconsistencia posicional creciente.

Este sentimiento, tal como las entrevistas presentadas permiten analizar, por común que aparezca entre los individuos pertenecientes a distintos grupos sociales, refleja condiciones bien distintas según se trabaje en el sector formal o informal de la economía (Infante y Sunkel, 2004), y según se disponga de uno o varios salarios o de acuerdo con el tipo de contrato. Sin embargo, la variedad estriba no solo en lo que suscita la inquietud, sino también en el modo como esta inquietud toma o no la forma de una preocupación crónica, y las maneras como se lidia con ella. Curiosamente, no son aquellos definidos por una mayor fragilidad "objetiva" quienes expresan, necesariamente, una mayor inquietud posicional. En todo caso, lo que aparece común y transversal en las entrevistas es el sentimiento masivo de no sentirse nunca definitiva o durablemente al abrigo de la desestabilización económica. Una inconsistencia susceptible de ser puesta a prueba por un gran número de factores.

\section{a) El despido y sus sombras}

En Chile, la desocupación tiene una enorme incidencia en la probabilidad de ser pobre o de recaer en la pobreza (Arzola y Castro, 2009). Pero más allá de las cifras, e incluso de la diversidad efectiva de mecanismos de protección y de indemnización de la que gozan los distintos asalariados, lo que interesa subrayar es el tipo de conciencia que expresan los individuos frente a esta eventualidad. Un sentimiento de intemperie social más o menos agudo, un sentimiento de impotencia más o menos pronunciado: "Es un sistema muy perverso, muy, muy cruel, la legislación no te apoya, no te protege, no hay ningún resguardo. A mí el seguro de cesantía me cubrió tres meses..." (hombre, ejecutivo). Un temor que acentúa la edad y sus consecuencias en las oportunidades laborales y que fue ampliamente recordado: "Aquí al tener 40 años ya eres viejo para el trabajo" (hombre, 49 años); "en este país de los 40 años para arriba y a somos viejos y somos caros, entonces en este momento para la empresa puedo ser muy caro, con el sueldo mío le pueden pagar a dos o tres personas y eso a veces me preocupa..." (hombre, 51 años); "los que vamos avanzando en edad vamos encontrando cada día más competencia y es más difícil desenvolverse, lo que engendra un tipo de ansiedad" (hombre, 44 años).

\section{b) La bancarrota}

Si los asalariados temen el despido, los empresarios $\mathrm{y}$ trabajadores por cuenta propia temen la quiebra. Por supuesto, las experiencias negativas no deben hacer olvidar la experiencia exitosa de tantos otros (o de las mismas personas en otros momentos de sus vidas). Pero una ansiedad común se inscribe en este horizonte. En verdad, su situación es paradójica. Por una parte, en las últimas décadas ha habido en Chile un mejoramiento más rápido del ingreso de los trabajadores independientes con respecto a los asalariados, al punto de que en el período de 1987 a 1995 el incremento promedio del ingreso fue del $90 \%$ en las categorías no asalariadas (empresarios y trabajadores por cuenta propia) y de solo $45 \%$ entre los asalariados (León y Martínez, 2007, págs. 316 y 321 ). Pero por otra, y en continuidad con lo que es una de las grandes características de este tipo de trabajadores, se expresa un permanente sentimiento de inquietud y desprotección. Su posición depende, antes que de muchas otras cosas, del dinamismo del mercado, y toda contracción de este tiene consecuencias por lo general directas en su nivel de ingresos: "Lo que pasa es que vas perdiendo la perspectiva a largo plazo, te vas metiendo en el lío y cada vez te levantas en la mañana y tu preocupación es pasar el día... Te vas dejando arrastrar y vas perdiendo la objetividad; hay gente que habla contigo, pero igual no la pescas, te vas involucrando emocionalmente..." (hombre, empresario).

\section{c) Las fluctuaciones del mercado}

La inquietud de inconsistencia posicional se hace patente en la conciencia que los entrevistados manifestaron al establecer vínculos entre cambios económicos globales y contingencias personales. En algunos, por ejemplo, es la apertura al mercado internacional la que indica, claramente, la bifurcación de sus existencias. Es el caso de esta mujer, aparadora de zapatos, cuya linealidad se corta "cuando empezó a entrar el zapato chino". El de una mujer de clase media alta es apenas distinto. Tuvo que comenzar a trabajar: "Cuando las cosas empezaron a ir mal en la fábrica de mi marido; mi marido tiene una fábrica industrial de bordados y cuando se abrieron tanto las puertas para que vinieran todos los (productos) chinos, sonamos". Vale la pena precisar este punto. Lo importante no es la plausibilidad de las interpretaciones avanzadas (un ámbito bien estudiado por los economistas a través, por ejemplo, de la propagación efectiva y regional de las crisis económicas - Daher, 2004), lo que importa retener es la fuerza de este repertorio cultural en la percepción del propio emplazamiento social. 


\section{d) El endeudamiento}

$\mathrm{Si}$ el endeudamiento concierne a muchos grupos sociales, entre los individuos entrevistados esta experiencia fue directamente enunciada por la mitad de la muestra y casi tres veces más personas que recordaron esta experiencia pertenecían a los sectores populares. Sin lugar a dudas, en esta diferencia hay que tener en cuenta la mayor o menor facilidad con que miembros de ciertas capas sociales pueden dar a conocer sus dificultades económicas a desconocidos. Sin embargo, y más allá de lo anterior, es posible plantear la hipótesis de que esta es una experiencia especialmente importante en los sectores populares, porque es en ellos donde el umbral del desequilibrio posicional se traspasa más rápidamente. En este punto, más allá de su similitud aparente, en los testimonios se describen dos grandes mecanismos. Por una parte, lo que se puede denominar el "desliz", el sentimiento casi constante de que dadas las insuficiencias monetarias y la falta de ahorros o de protección social, en todo momento y ante cualquier adversidad es posible resbalar hacia el sobreendeudamiento. Por otra, un mecanismo de "engranaje" en el que lo que prima en el relato es el endeudamiento producto de un encadenamiento imparable de eventos, como si una vez puesto en marcha el engranaje no hubiera detención posible y la "máquina" se volviera una intriga implacable: "Estuvimos harto endeudados porque mi marido tuvo un accidente y entonces estuvo tres meses sin trabajar. $Y$ las cuentas empiezan a llegar y llegar y lo que uno va ganando es para solventar el gasto de la casa, pa' tener pa' comer, pero las cuentas se van acumulando... Pucha, tenís que tratar de apretarte un poquito más pa' poder pagar, sobre todo pagai primeramente la luz y el agua que son gastos fundamentales, pero igual las deudas de las casas comerciales van subiendo..." (mujer, recicladora de papel).

\section{e) Turbulencias, toboganes y montañas rusas}

Por último, en una lista no exhaustiva, también es posible hacer referencia a otro tipo de experiencias que, en su versión más amplia, desarrollaremos más adelante. ¿De qué se trata? Del hecho de que la inconsistencia posicional, cualquiera sea su relación con un evento socioeconómico (despido, bancarrota, coyuntura o endeudamiento), diseña un abanico de experiencias sociales según que estos eventos marquen una turbulencia pasajera ("seguíamos viviendo en un súper buen departamento, pero mis papás nos tenían que ir a dejar comida a la casa porque no teníamos plata para comprar comida..." —hombre, ingeniero), un tobogán durable (es decir, un proceso marcado de movilidad social descendente o de ingreso en la pobreza) o una montaña rusa: a una fase de rápido descenso le sigue una fase, por lo general más lenta, de recuperación de una posición social. En los estudios sociológicos estas situaciones son por lo general evaluadas mediante técnicas estadísticas, con el fin de medir el tiempo que las personas que "caen" tardan en "levantarse". Estos análisis son sin duda preciosos, puesto que el impacto de la caída (en la pobreza) no es el mismo en función de su duración. Pero en estos análisis se minimiza, al menos en parte, un aspecto particularmente subrayado en estos testimonios: a saber, que estas "subidas" o "bajadas" afirman y se articulan en el sentimiento generalizado y constante de inconsistencia posicional.

\section{Temores políticos}

En el contexto de la incidencia de la política en la sociedad chilena, los años 1973 y 1989-1990, incluso en el momento de las entrevistas en el período 2007-2009, y la posibilidad de alternancia política que se produjo en el año 2010 (con la victoria de la Alianza) aparecen, con intensidades obviamente distintas y aun como inquietud imaginaria, como una fuente de inconsistencia posicional. Una experiencia generalizada de inquietud que, desde otros presupuestos teóricos, ha sido descrita como un conjunto de "miedos" propios de la sociedad chilena actual (PNUD, 1998 y 2002).

Obviamente, este sentimiento tiene profundas raíces históricas. Pero el temor que se enuncia frente a la política no puede ser pensado como una continuidad: no es ya de índole colectiva, bajo la forma histórica de un miedo frente al desorden generalizado (incluso cuando el tema no está del todo ausente), sino que es más bien un temor personalizado, el sentimiento, marcadamente individual, de que la política se añade a la larga lista de factores que pueden desestabilizar una situación o una trayectoria social (Tironi, 2009, pág. 92).

El punto es central. Por una parte, porque aparece como un resultado empírico contraintuitivo, ya que cuestiona lo que ha sido considerado como una evidencia: una sociedad signada por la continuidad y un debilitamiento del factor político debido a la adhesión de las principales coaliciones de gobierno a pautas comunes de gestión económica. Una lectura que se ha hecho eco de tesis que sostienen la disminución sensible del impacto de los cambios políticos en la vida social ordinaria de las personas a nivel global. Pero en los resultados aquí expuestos resalta que esta tesis debe ser morigerada para el caso chileno. El cambio político es percibido por muchos individuos como una fuente casi 
directa de desestabilización posicional. Un ingeniero lo expresó con transparencia: "El tema político yo creo que tiene importancia porque te afecta la vida personal, de familia, de trabajo ... No sé, por ejemplo, ahora hace poco con todos los anuncios que hicieron, resulta que las rentabilidades de las empresas se recalcularon y los valores de las acciones cayeron... en ese sentido te afecta". O como lo expresa un estafeta: "A mí no me gusta la política, pero es que uno está inserto en la política, uno no puede hacerse a un lado porque está en todo".

Este temor a los efectos de la política en la vida ordinaria está anclado de manera relevante en la memoria de la dictadura. "Fue bien complicado, fue una etapa bien dura, dura, porque igual viste movimientos que te llamaron la atención, que tú nunca los habías visto, vi pasar bayonetas, vi pasar tanques, vi pasar soldados por la calle... pasar rasantes los aviones... Eso te marca, te impacta..." (mujer, paramédica). En verdad, los testimonios y el temor que se expresa toman ribetes muy similares, al punto de que es posible hablar de una impactante estandarización narrativa: presencia militar, maltratos, rumores, entre otros. La gran mayoría de los entrevistados tenía un recuerdo preciso de ese 11 de septiembre. Un sentimiento de temor generalizado que se encuentra incluso entre aquellos que tenían simpatía por el régimen militar: "Mi mamá nos decía:- 'Tengan cuidado niñitas si algún día ven un auto tipo chevy nova, eran unos modelos así con vidrios oscuros con unos gallos con bigotes adentro, si ven eso aléjense porque un día las pueden agarrar, meter al auto y no las vemos más...'-'Ay, pero por qué?'-'Porque son los servicios de seguridad y así como se agarran a los comunistas y a los socialistas, pueden encontrar una niñita que les gusta y la hacen..." (mujer, periodista).

Este temor político fue evidentemente un agente activo de inconsistencia, que también se expresó a través de consecuencias muy concretas y materiales que este evento tuvo a nivel social y económico como factor, por ejemplo, de empobrecimiento familiar. Un agente también activo, pero en sentido opuesto, entre los partidarios de la dictadura: "Cuando mi padre fue despedido de Codelco - recuerda este abogado- y la economía se empezó a liberalizar más, había que estar preparado para eso, y mi papá no estaba preparado ... él venía de una cultura, digamos, que tenía que ser empleado y pasar a una que como emprendimiento requiere de otras herramientas, fue súper difícil". Otros, en una lógica similar, recuerdan cómo el golpe desestabilizó psicológicamente a uno de sus padres o les impuso un desempleo prolongado: "Yo nací con un papá cesante y marcado por los milicos, o sea, mi viejo estuvo ocho años en la casa, ocho años sin poder encontrar trabajo...".

La política como factor de inconsistencia posicional apareció asimismo entre aquellos que se autodescribieron como partidarios de la dictadura: "La Unidad Popular es lo que más marcó mi vida porque dormí tres años vestida con un arma al lado, tres años, esto era en el campo. Siempre nos entraban a matar y mataron a todos los vecinos de nosotros que eran familias igual que nosotros, los mataron a todos... Entraron y los mataron... Los mataron la gente de la Unidad Popular, del MIR. La gente se olvidó de eso, pero yo vi familias enteras que habían sido muertas, y le entraban a tomar el fundo y los mataban". Esta abogada no duda en afirmar que la época de la Unidad Popular fue "la época más horrorosa, más odiosa, el mayor odio que he visto en mi vida ha sido en esa época". En muchos, incluso, su impacto es tal que nos remite a la experiencia evocada en el párrafo anterior sobre la montaña rusa, a tal punto que aquellos que habían perdido un empleo, lo recuperaron, u otros vieron su situación deteriorarse y mejorarse rápidamente.

Pero este efecto no se reduce a estas experiencias, sino que continúa a lo largo de estas décadas. Una productora recuerda, por ejemplo, que su participación en uno de los spots de la campaña por el NO, en 1989, tuvo consecuencias económicas para ella, puesto que un cliente que la reconoció se cambió de empresa. Y durante las entrevistas efectuadas entre 2008 y 2009 , el temor del cambio de mayoría política fue activo en un porcentaje no menor de las personas entrevistadas. Lo que se encuentra entonces, si seguimos nuestro material empírico, es un miedo difuso que halla en la inquietud posicional una de sus más durables expresiones. Algo que aparece como común en los testimonios de los actores es el hecho, tan simple y tan profundo en sus consecuencias, de que en Chile - para volver a decirlo con las palabras de uno de nuestros entrevistados- la política afecta a la vida personal, la familia y el trabajo, porque la política está en todo.

\section{Peligros y amenazas urbanas}

La tercera fuente de inconsistencia posicional es uno de los principales marcadores de la distancia social entre actores hoy en día en Chile. Si el temor ante las acechanzas urbanas no está ausente entre las capas medias, su expresión es mayúscula en los sectores populares y sobre todo entre las mujeres de estos sectores.

Por una parte, la ciudad de Santiago posee una morfología social marcada por una pronunciada polarización 
social y segregación residencial. La geografía social entre las clases está bien reflejada e inscrita en la ciudad: entre las tres comunas más ricas, por ejemplo, los niveles de pobreza solo conciernen a menos del $2 \%$ de la población, cifra que alcanza a casi un $40 \%$ entre los residentes de las comunas más pobres (De Mattos, 2004, pág. 28). O si se prefiere, las personas de más altos ingresos solo residen en 6 de las 34 comunas de la Región Metropolitana, y los más pobres en solo 20 comunas (Rodríguez y Winchester, 2004, pág. 116). Esta división ha permitido a algunos analistas subrayar la pertinencia de la hipótesis de las "dos ciudades", al punto de que las áreas ricas y pobres de Santiago serían independientes entre sí (41\% de los barrios de la ciudad son socialmente homogéneos).

Por otra parte, detrás de estos conglomerados estadísticos aparece, a nivel local y dentro de los barrios, una marcada fragmentación de situaciones y experiencias. En breve, tras la innegable polarización urbana de Santiago se esconde una miríada de microfracturas sociales. Esto es particularmente visible entre los sectores populares. En los denominados estratos C, pero sobre todo en los $\mathrm{D}$, se advierte un muy alto nivel de heterogeneidad interna. Algunos se aproximan en sus condiciones de vida a los sectores de extrema pobreza, mientras que otros se acercan a estándares de clase media baja (Rasse, Salcedo y Pardo, 2009, pág. 21). Es decir, detrás de la vivienda popular se ocultan realidades muy heterogéneas según se viva en una villa o en una población, y según se viva o no en un barrio cuya reputación ha deteriorado o no el valor de la casa adquirida (o en vías de adquirirse), sin olvidar, por supuesto, la inseguridad que se experimenta en el espacio urbano.

En todo caso, es dentro de los barrios populares, en esos espacios segregados y con fuertes desigualdades a nivel de la calidad de los servicios públicos, donde se expresa principalmente el sentimiento de que la ciudad es una fuente mayor de amenaza posicional. Cuatro grandes modos narrativos se repiten y se superponen en los relatos encontrados.

Primer modo: el barrio "de uno", no siendo bueno, no es tan malo como otros. Se trata de una actitud observada también en muchos otros lugares y es testimonio no solo de la importancia de las estrategias de microsegregación dentro de las poblaciones o de los barrios populares, sino también de una de las grandes particularidades de la lógica de comparación entre actores urbanos. Aquí, el grupo de referencia con el que los individuos se comparan incluye siempre a personas que residen en barrios "peores". ¿Por qué? Porque cualquiera que sea el deterioro, es imposible para los actores no percibir que es en ese espacio donde, sea como fuere, se desenvuelven sus vidas. El esfuerzo de dignificación indispensable los conduce a esta diferenciación: "Es tranquilo el barrio (en Quilicura), súper tranquilo adonde yo vivo. Yo vivo en la entrada casi, porque hay otra parte que es bien mala, pero que es bien adentro y yo encontré ese lugar allí más tranquilo" (mujer, personal de limpieza). "Bueno, el lado de nosotros es súper tranquilo, porque son pura gente de trabajo", pero "sí poh, hay problemas, pero ya p'al otro lado, el otro lado es donde hay gente mala ... hay más niños desordenados adentro. Pero por lo menos este lado es súper tranquilo, es súper bueno" (mujer, recicladora de papel).

Segundo modo: la llegada de lo que muchas de las personas entrevistadas designan como los "nuevos", y con ellos, en una causalidad que la narración establece como una evidencia, el incremento de los robos y otro tipo de delitos que imponen la necesidad de estar siempre en alerta, en vigilia: "Aquí nos conocimos todos en la villa, que son como 120 departamentos, entonces ya nos ubicamos todos, y de repente llega gente de afuera que a veces uno no conoce y que han ido cambiando el barrio" (mujer, cocinera). Ahora bien, ¿quiénes son estos "otros"? ¿De dónde vienen? ¿No estaríamos aquí en presencia de una infraclase en el seno de los sectores populares? En resumen, ¿existe o no una diferencia social y cultural mayor entre los unos y los otros? Con cautela, el material aquí expuesto permite dar una respuesta a algunas de estas preguntas. Si algunos de estos "otros", nuevos habitantes, pueden proceder de las últimas olas de migración a la ciudad de Santiago, y según ciertos estudios provienen de sectores rurales, se caracterizan empero por lo general por una marcada similitud social con los "viejos" habitantes. En el fondo, estamos en el universo - bien analizado por Norbert Elias- de la configuración entre los "establecidos" y los "marginales" (Elias y Scotson, 1965). Como en su célebre estudio, aquí también poco importa la existencia o no de diferencias reales entre unos y otros. Lo relevante es que esta disimilitud temporal de residencia engendra sentimientos opuestos en unos y otros, porque inevitablemente, como los testimonios recolectados lo ejemplifican a cabalidad, los viejos habitantes - los "establecidos" - perciben a los nuevos —en el lenguaje de Elias, los "marginales"como una amenaza multiforme para el control urbano que ejercieron hasta entonces.

Tercer modo: la droga en cuanto alarma de tipo territorial-exógena. En este registro, la presencia reiterativa de la droga en el discurso de los habitantes, y sobre todo de las mujeres de los sectores populares, testimonia un temor posicional que se encarna con un 
temor propiamente materno: el que los hijos caigan en su consumo, se vean envueltos en el narcotráfico y sean víctimas de la violencia que este produce en los barrios. El narcotráfico genera una ansiedad posicional particular: "En la comuna de La Cisterna, bueno, hasta hace un par de años atrás era una comuna excelente, súper tranquila, era increíble vivir ahí, uno podía salir toda la noche y jamás te pasaba nada, pero ahora se ha echado a perder por la cuestión de la droga, de las pandillas... En parte a causa de gente que llegó de afuera y se instaló con su negocio maldito y se empezaron a echar a perder los jóvenes, donde ha habido hasta suicidios, hasta asesinatos, o sea, una cuestión horrible... Hace dos meses enterramos a un chico que se crió con mis hijas..." (mujer, vendedora en feria). Un eco similar entrega esta ama de casa residente en otro barrio: "El barrio ha cambiado porque ha llegado mucho lo que es la droga, esto que los niños se meten a la onda de las bandas, que la violencia, que se ve mucho robo, entonces esto es el cambio...".

Cuarto modo: irse. Si "irse" aparece como la inevitable conclusión de los momentos narrativos precedentes, esta posibilidad está lejos de ser común a todos. En primer lugar, porque incluso si el anhelo pudiera ser masivo, no todos tienen la posibilidad de pensar en (y menos poner en práctica) una solución de este tipo. Sin embargo, según una encuesta, ya en 2001 un $65 \%$ de los habitantes de conjuntos de vivienda de muy bajo costo en comunas pobres querían irse de sus viviendas sociales (citado en Dammert y Oviedo, 2004, págs. 281 y 282). En todo caso, la imposibilidad de hacerlo, como lo atestigua una de las entrevistadas, deriva en un sentimiento de encierro y de asignación urbana: "Yo lo único que le pediría a Dios, es de vender mi casa donde vivo, irme a otro barrio que sea un poquito mejor... Yo lo único que quiero, por ejemplo ahora, es irme de donde vivo (comuna de El Bosque), porque cuando yo llegué a vivir ahí no era así poh y ahora se ha transformado..." afirma esta empleada doméstica. En segundo lugar, porque a pesar de los temores no todos quieren irse del barrio, a tal punto los afectos urbanos son en algunos reales y profundos. Queda entonces la acción colectiva con sus posibilidades y sus límites, la afirmación del espacio urbano como una manera de manifestar sus derechos en él.

Si en esta subsección se ha privilegiado la experiencia de las mujeres de sectores populares, es con el fin de subrayar la especificidad de esta modalidad de inconsistencia posicional. Por supuesto, la preocupación por el robo e incluso la inseguridad urbana está presente entre las capas medias y altas. No obstante, el temor se concentra en los grupos socioeconómicamente más vulnerables, como también las denuncias por delitos y crímenes (Dammert y Oviedo, 2004). Cuando la inseguridad urbana se manifiesta entre las capas medias y altas, esta experiencia no es solo puntual, sino que es, en sí misma, un factor de inconsistencia posicional. Por el contrario, entre los sectores populares, y sobre todo entre las mujeres, la inseguridad, cuando aparece, genera inmediatamente otra experiencia, sin duda más ansiógena, como es el temor de ver su posición social temporal o definitivamente desestabilizada por las transformaciones sociourbanas.

\section{La lógica imparable de los "accidentes"}

La última fuente de desestabilización que se mencionará es menos homogénea que las precedentes. Sin embargo, es en su heterogeneidad donde estriba su profunda unidad. Se trata de un conjunto de factores disímiles, por lo general presentados y relatados como "accidentes" vitales, que vienen a perturbar una trayectoria, un proyecto de vida o una posición social. Ahora bien, y por cierto, toda vida humana está sujeta a sucesos imprevisibles. La contingencia, la ocurrencia de eventos que suceden en la vida es una marca indeleble de nuestras existencias. No obstante, no todos ellos tienen la capacidad percibida por los actores, real o supuesta, de torcer el rumbo de la vida o ponerlo en serio riesgo. Lo que define esencialmente esta lógica de los accidentes es la importancia que se les otorga y el papel narrativo que terminan poseyendo en la descripción de las trayectorias.

Diferentes entre sí, estos "accidentes" han sido masivamente recordados por las mujeres de los sectores populares (la casi totalidad de ellas recurrieron a esta forma narrativa), en comparación con menos de un cuarto de hombres y mujeres de capas medias y altas y casi la mitad de los hombres de sectores populares entrevistados. Muchas veces estos accidentes son presentados como experiencias puntuales que desestabilizan, pero no consiguen transformar dramáticamente el trayecto de vida. Otras veces, eventos de este tipo terminaron por revelarse altamente significativos en sus consecuencias posicionales. El "accidente" se convierte en una "catástrofe". Robos, por ejemplo, que se revelarán más o menos definitivos en sus consecuencias, como el de esta mujer de sectores populares que, al perder sus papeles en el evento, será despojada de su casa al no poder acreditar su derecho de propiedad. Embarazos no deseados que precipitaron uniones matrimoniales o conyugales, mayoritariamente entre los miembros — hombres y mujeres— de sectores 
populares; o la caída en las drogas que compromete todo el trayecto familiar.

Es posible precisar aún más el punto: en todas partes la vida está marcada por accidentes trágicos, pero estos no solo repercuten de manera diferente según los grupos sociales, sino que también son más o menos absorbidos por las posiciones sociales que detentan los individuos. Mientras más recursos se vinculen a estas, menores son las repercusiones "inmediatas" en dichas posiciones que tienen las tragedias de la existencia. Por el contrario, y es el sentido de los testimonios recabados, en el Chile de hoy las vicisitudes trágicas de la existencia se traducen muchas veces en desestabilizaciones posicionales.

La lista es variada y larga. Para algunos fue la violencia sexual intrafamiliar lo que desencadenó un largo y accidentado proceso de errancia social o un conflicto familiar. Para otros, fue una experiencia de depresión o bien una enfermedad que, debido a los costos que generó, puso a prueba no solo la solidaridad intrafamiliar, sino también la capacidad de hacer frente a deudas que se convirtieron en crónicas: "Tengo deudas de hace cinco años atrás, del cáncer; me hice de una deuda que no la puedo pagar; la he renegociado cinco veces, de \$250.000 he pasado al millón de pesos..." (hombre, vendedor).

Se trata de experiencias propiamente existenciales y lo que en ellas debe retener la atención son sus consecuencias en términos de inconsistencia posicional. ¿Es necesario decirlo? Estas experiencias jamás se reducen a este aspecto y, sin lugar a dudas, en los relatos reunidos no es necesariamente esta faceta la que es subrayada. El dolor insondable y el duelo interminable, el sentimiento de una vida que se detuvo o de una herida que nunca terminará de cicatrizar forman parte de esta verdad.

\section{V}

\section{De la inconsistencia posicional a los individuos}

En el marco de la sociedad chilena, esta experiencia de inconsistencia posicional, transversal a muchos estratos sociales, es tanto más relevante cuanto el país ha conocido tasas importantes de crecimiento económico en las últimas décadas, que se han traducido, a pesar del mantenimiento de las desigualdades sociales, en un indudable sentimiento de mejoría y de prosperidad (Ffrench Davis, 2008). Sentimiento que se aprecia, por ejemplo, en las encuestas nacionales realizadas por el Informe de Desarrollo Humano del Programa de las Naciones Unidas para el Desarrollo (PNUD) entre 1998 y 2008, que reflejan globalmente que los individuos perciben que su situación personal mejoró inequívocamente en las últimas décadas (Güell, 2009). En resumidas cuentas, la sociedad chilena ha conocido un proceso de enriquecimiento colectivo que se ha traducido en el sentimiento, mayoritario entre los chilenos (hasta un 60\%), de que sus condiciones de vida son mejores o mucho mejores que las de sus padres (Torche y Wormald, 2007, pág. 355).

Sin desconocer lo anterior, para concluir vale la pena interesarse en lo que esta inquietud multiforme revela sobre la sociedad chilena. Esquematizando los resultados, puede decirse que la inconsistencia posicional es masiva entre los sectores populares y por lo general se vincula a factores económicos y urbanos, pero también a efectos desestabilizantes producidos por los "accidentes" existenciales. Cabe notar que en este sector la política aparece como un factor de menor relevancia. Por el contrario, entre las capas medio-altas las principales razones de la inconsistencia radican en aprensiones de índole política y económica, así como, aunque más tenuemente, en algunos temores relacionados con "accidentes", mientras que la dimensión urbana está particularmente ausente. Pero a pesar de estas diferencias, en el presente trabajo se llega a una conclusión principal: en lo concerniente a la estratificación social es preciso reconocer que detrás de la pluralidad de lugares existe hoy en Chile un paradójico sentimiento compartido de inconsistencia posicional.

En esta inquietud plural es posible advertir la presencia de una variante particular del proceso de individualización (Beck, 1998; Bauman, 2003), en que los individuos sienten que tienen que hacerse activamente cargo de un conjunto de aspectos que, en otras sociedades o en la misma sociedad chilena en otros momentos de su historia, fueron responsabilidad de las instituciones o aseguradas estructuralmente por el hecho de pertenecer a un estrato social (Araujo, 2009). Es en tal sentido que en este trabajo se considera que los estudios sobre la estratificación social deberían prestar especial atención 
a la inconsistencia posicional. No solo porque esta realidad, pese a la disimilitud de sus fuentes, introduce una lectura transversal entre estratos, sino porque se encuentra en el origen de muchos otros fenómenos presentes en el país, comenzando, por ejemplo, con el exceso de demandas de protección que los individuos dirigen a la familia y que no sería ajeno a algunas de sus dificultades actuales (Valenzuela, Tironi y Scully, 2006). También se visualiza la necesidad de desarrollar estrategias de redes de favores y reciprocidades, a fin de paliar esta inquietud posicional generando una suerte de "sistema funcional alternativo" (Robles, 2000) o constituyendo estas estrategias en prácticas sociales con una función incluyente y estructurante (Barozet, 2006).

Para los individuos, la realidad de la inconsistencia posicional tiene una doble consecuencia. Por una parte, induce a los actores a tejer redes sociales para protegerse de los riesgos. Por otra, ante la conciencia que estos tienen de sus límites, dado el carácter estructural, plural y permanente de la inconsistencia, se refuerza el sentimiento - en verdad, la filosofía - de que en la vida hay que arreglárselas solo. En Chile, los individuos se perciben como obligados a buscar respuestas por sí mismos a una serie de falencias estructurales, lo que inevitablemente incrementa las inseguridades y las diferencias entre los actores. Un sentimiento que en su raíz, cualquiera sea el peso inequívoco que le corresponde a los procesos económicos, no puede en absoluto reducirse a esta sola dimensión. La estabilidad posicional que ayer era transmitida por la alcurnia o el apellido, por la "decencia" mesocrática, y para otros por ciertas formas de protección salarial y comunitaria, es percibida cada vez más como una realidad globalmente inconsistente y que requiere, de manera constante, el despliegue de estrategias indisociablemente personales, familiares y sociales. En consecuencia, la inconsistencia posicional aparece como un fenómeno estructural de primera importancia en la sociedad chilena contemporánea.
Aguilar, O. (2009), "Principios de diferenciación material y simbólica en la estratificación social", El arte de clasificar a los chilenos, A. Joignant y P. Güell (coords), Santiago de Chile, Ediciones UDP.

AIM (Asociación Chilena de Empresas de Investigación de Mercado) (2000), Metodología de medición de niveles socioeconómicos. Método utilizado por AIM Chile [en línea] http://www.aimchile. cl/G1.asp.

Araujo, K. (2009), Habitar lo social, Santiago de Chile, LOM Ediciones.

Arzola, M.E. y R. Castro (2009), "Determinantes de la movilidad de la pobreza en Chile (1996-2006)", El arte de clasificar a los chilenos, A. Joignant y P. Güell (coords.), Santiago de Chile, Ediciones UDP.

Barozet, E. (2006), "El valor histórico del pituto: clase media, integración y su diferenciación social en Chile", Revista de sociología, $\mathrm{N}^{\mathrm{o}} 20$, Santiago de Chile, Facultad de Ciencias Sociales, Universidad de Chile.

(2002), L'échange de faveurs au sein des couches moyennes chiliennes: de l'entraide informelle à la régulation sociale, tesis, École des hautes études en sciences sociales (EHEss).

Barozet, E. y V. Espinoza (2009), “¿De qué hablamos cuando decimos "clase media"? Perspectivas sobre el caso chileno", El arte de clasificar a los chilenos, A. Joignant y P. Güell (coords.), Santiago de Chile, Ediciones UDP.

Bauman, Z. (2003), Modernidad líquida, Buenos Aires, Fondo de Cultura Económica.

Beck, U. (1998), La sociedad del riesgo, Barcelona, Paidós.

Boltanski, L. (1982), Les cadres, París, Minuit.

Castel, R. (1995), Les métamorphoses de la question sociale, París, Fayard.

Contardo, O. (2008), Siútico, Santiago de Chile, Vergara.

Contreras, D., O. Larrañaga y J. Litchfield (2001), "Poverty and income distribution in Chile 1987-1998: new evidence", Cuadernos de economía, vol. 38, No 114, Santiago de Chile, Pontificia Universidad Católica de Chile.
Contreras, D. y otros (2005), "Movilidad y vulnerabilidad en Chile", Foco, $\mathrm{N}^{\circ}$ 56, Santiago de Chile, Expansiva.

Daher, A. (2004), "Riesgo-país versus riesgo-región: Santiago en el MERCOSUR", Santiago en la globalización: ¿ una nueva ciudad?, C. de Mattos y otros, Santiago de Chile, Ediciones Sur.

Dammert, L. y E. Oviedo (2004), "Santiago: delitos y violencia urbana en una ciudad segregada", Santiago en la globalización: ¿una nueva ciudad?, C. de Mattos y otros, Santiago de Chile, Ediciones Sur.

De Mattos, C.A. (2004), "Santiago de Chile: metamorfosis bajo un nuevo impulso de modernización capitalista", Santiago en la globalización: ¿una nueva ciudad?, C. de Mattos y otros, Santiago de Chile, Ediciones Sur-Eure libro.

Dubet, F. y D. Martuccelli (2000), ¿En qué sociedad vivimos? Buenos Aires, Losada.

Ehrenreich, B. (1989), Fear of Falling, Nueva York, Pantheon Books.

Elias, N. (1982), La sociedad cortesana, México D.F., Fondo de Cultura Económica.

Elias, N. y J. Scotson (1965), The Established and the Outsiders, Londres, Sage.

Espinoza, V. (2002), "La movilidad ocupacional en el Cono Sur. Acerca de las raíces estructurales de la desigualdad social", Proposiciones, $\mathrm{N}^{\circ}$ 34, Santiago de Chile, Ediciones Sur.

Ffrench Davis, R. (2008), Chile entre el neoliberalismo y el crecimiento con equidad, Santiago de Chile, J.C. Sáez Editor.

García Canclini, N. (1995), Consumidores y ciudadanos, México, D.F., Grijalbo.

Güell, P. (2009), "En Chile el futuro se hizo pasado: ¿y ahora cuál futuro?", El Chile que viene. De dónde venimos, dónde estamos y a dónde vamos, Santiago de Chile, Ediciones UdP.

Infante, R. y G. Sunkel (2004), Chile: trabajo decente y calidad de vida familiar, 1990-2004, Santiago de Chile, Organización Internacional del Trabajo (OIT).

Kessler, G. y V. Espinoza (2007), "Movilidad social y trayectorias ocupacionales en Buenos Aires. Continuidades, rupturas y paradojas", Estratificación y movilidad social en América 
Latina, R. Franco, A. León y R. Atria (coords.), Santiago de Chile, LOM Ediciones.

Kocka, J. (1989), Les employés en Allemagne (1860-1980), París, École des hautes études en sciences sociales (EHEss).

León, A. y J. Martínez (2007), "La estratificación social en Chile hacia fines del siglo XX, Estratificación y movilidad social en América Latina, R. Franco, A. León y R. Atria (coords.), Santiago de Chile, Lom Ediciones

Lomnitz, L. y A. Melnick (1991), Chile's Middle Class. A Struggle in the Face of Neoliberalism, Londres, Lynne Rienner Publishers.

Minujín, A. (1993), Cuesta abajo, Buenos Aires, UNICEF/Losada.

Molina, S. (2005), Es el tiempo de la equidad, Santiago de Chile, Academia Chilena de Ciencias Sociales, Políticas y Morales/ Instituto de Chile/Banco del Desarrollo.

Nun, J. (1969), "Superpoblación relativa, ejército industrial de reserva y masa marginal”, Revista latinoamericana de sociología, vol. 2, Buenos Aires.

Núñez, J. y L. Miranda (2009), "La movilidad intergeneracional del ingreso y la educación en Chile", El arte de clasificar a los chilenos, A. Joignant y P. Güell (coords.), Santiago de Chile, Ediciones UDP.

Paugam, S. (1996), L'exclusion: l'état des savoirs, París, La Découverte.

PNUD (Programa de las Naciones Unidas para el Desarrollo) (2002), Nosotros los chilenos: un desafio cultural, Santiago de Chile. (1998), Las paradojas de la modernización, Santiago de Chile.

Portes, A. y K. Hoffman (2007), "Las estructuras de clase en América Latina: composición y cambios en la época neoliberal", Estratificación y movilidad social en América Latina, R. Franco, A. León y R. Atria (coords.), Santiago de Chile, Lom Ediciones.

Portocarrero, G. (comp.) (1998), Las clases medias: entre la pretensión y la incertidumbre, Lima, Sur-Oxfam.
Quijano, A. (1971), Redefinición de la dependencia y proceso de marginalización en América Latina, Santiago de Chile, Instituto Latinoamericano y del Caribe de Planificación Económica y Social (ILPES).

Ramos, J. y otros (2004), Cómo ha cambiado la vida de los chilenos, Santiago de Chile, Instituto Nacional de Estadísticas (INE).

Rasse, A., R. Salcedo y J. Pardo (2009), "Transformaciones económicas y socioculturales: ¿cómo segmentar a los chilenos hoy?”, El arte de clasificar a los chilenos, A. Joignant y P. Güell (coords.), Santiago de Chile, Ediciones UDP.

Robles, F. (2000), El desaliento inesperado de la modernidad, Santiago de Chile, RIL Editores.

Rodríguez, A. y L. Winchester (2004), "Santiago de Chile: una ciudad fragmentada", Santiago en la globalización: ¿una nueva ciudad?, C. de Mattos y otros, Santiago de Chile, Ediciones Sur.

Sánchez, J.F. (2009), Las estrategias relacionales de las clases medias en Cali-Colombia, Bruselas, Universidad Católica de Louvain.

Tironi, E. (2009) "Identidad y relatos nacionales", El Chile que viene. De dónde venimos, dónde estamos y a dónde vamos, Santiago de Chile, Ediciones UDP.

Torche, F. (2005), "Unequal but fluid social mobility in Chile in comparative perspective", American Sociological Review, vol. 70, $\mathrm{N}^{\mathrm{o}} 3$, Nashville, Tennessee, American Sociological Association.

Torche, F. y G. Wormald (2007), "Chile, entre la adscripción y el logro", Estratificación y movilidad social en América Latina, R. Franco, A. León y R. Atria (coords.), Santiago de Chile, Lom Ediciones.

Valenzuela, J.S., E. Tironi y T.R. Scully (comps.) (2006), El eslabón perdido, Santiago de Chile, Taurus Editores.

Wilson, W.J. (1996), Jobless Ghetto, Nueva York, Knopf.

(1987), The Truly Disadvantaged, Chicago, University of Chicago Press.

Whyte, W.H. Jr. (1957), The Organization Man, Nueva York, Doubleday Anchor Books. 